\title{
Diagnostics of Gearboxes of Mining Belt Conveyors Using Floating Spectral Masks
}

\author{
Evgeniy Kuzin ${ }^{1 *}$, Boris Gerike ${ }^{2,3}$, Mariya Mamaeva ${ }^{1}$, and Kumar Singh $^{4}$ \\ ${ }^{1}$ Branch of T.F. Gorbachev Kuzbass State Technical University in Prokopievsk, 653039, Prokopievsk, \\ Russian Federation \\ ${ }^{2}$ Federal Research Center of Coal and Coal Chemistry SB RAS, 650003, Kemerovo, Russian \\ Federation \\ ${ }^{3}$ T.F. Gorbachev Kuzbass State Technical University, 650000, Kemerovo, Russian Federation \\ ${ }^{4}$ Indian Institute of Technology, Mining Engineering Department, 110016 Hauz Khas, New Delhi, \\ India
}

\begin{abstract}
The article shows the relevance of improving the maintenance system of belt conveyors. The work features of mining gearboxes and the complexity of diagnosing the processes of wear in their elements are considered. On the one hand, the variable character of the load and changeable speed of the conveyor in accordance with the needs of the technological process from another part interferes in the operation of diagnostic systems. The results of the distribution of the overall level of vibration on the same type of gearboxes show different rates of degradation of their nodes. A solution to the problem of assessing the technical condition of the gearbox elements using the "floating" reference spectral masks is proposed. Spectral masks are created for several speeds of the belt movement. The amplitude levels of the velocity vibration characterize defects. They are changing depending on the frequency. They so to say "float". The spectral masks of the "warning" level and the results of assessing the state of the gearbox with their use are shown.
\end{abstract}

\section{Introduction}

The presence of accidental impulses interferes with the diagnostic system work. It can be or cannot be connected with the other machines damages.

The relevance of the topic of improving the maintenance of gearboxes of mine belt conveyors is confirmed by studies of Russian and foreign authors. So in the works [1 - 4] it is shown that the detection of damage in bearings and gears of reducers is one of the most intensively studied problems on monitoring the condition of equipment in the foreign literature. For mechanical systems used in the mining industry, the problem of sudden failure can be caused by a short-term local overload of the contacting surfaces in the gear pairs or bearings. The authors also show that certain operating conditions for underground equipment are required to adjust the existing diagnostic methods or even to develop new approaches of the technical condition assessment. [2]. The work of mining machines is

\footnotetext{
${ }^{*}$ Corresponding author: kuzinevgen@gmail.com
} 
carried out with a variable load character.There is often an interference overlay from operating equipment on the informative signal of vibration analysis, especially in the lowfrequency field. Random impulses interferes with the operation of diagnostic systems. It can or cannot be due to damage to other machines.

Malfunction and failure of the mining machine should be considered as unavoidable during operation, but as a result of degradation and wear. Condition monitoring allows you to define scenarios for the development of these processes. As a rule, a sudden stop of the conveyor due to a gear tooth failure is the result of several events [3]. The main ones are the violation of the geometry of friction pairs (misalignment of the shaft and gear), frictional depriciation, misalignment of the shafts of the electric motor and the gearbox (centering), the presence of imbalance. Frictional wear is caused by the ingress of particles of dust, water, and the metal friction itself. Timely cleaning of lubricating oil (or its complete replacement) will extend the life of bearings and gears. The elimination of the identified imbalance and misalignment problems leads to a depreciation decrease of the gearbox. If the vibration parameters characterizing the bearing defects are detected before it will be completely destroyed, the repair costs will be much lower. To replace bearings is simplier and cheaper than to build up and grind shafts or to change a gear because of a broken tooth. In addition, when the gearbox is suddenly jammed, there will be dynamic stresses on the belt, which can be the cause of its break. This can result to a serious accident.

Thus, the prediction of the degradation processes of the belt conveyor reducer will not only help to reduce maintenance costs, but will also improve the safety of work during their operation. Figure 1 shows the graphs of the normal distribution of the total vibration level at the characteristic points of the shaft belt conveyor reducers according to the mean square value of the vibration velocity.

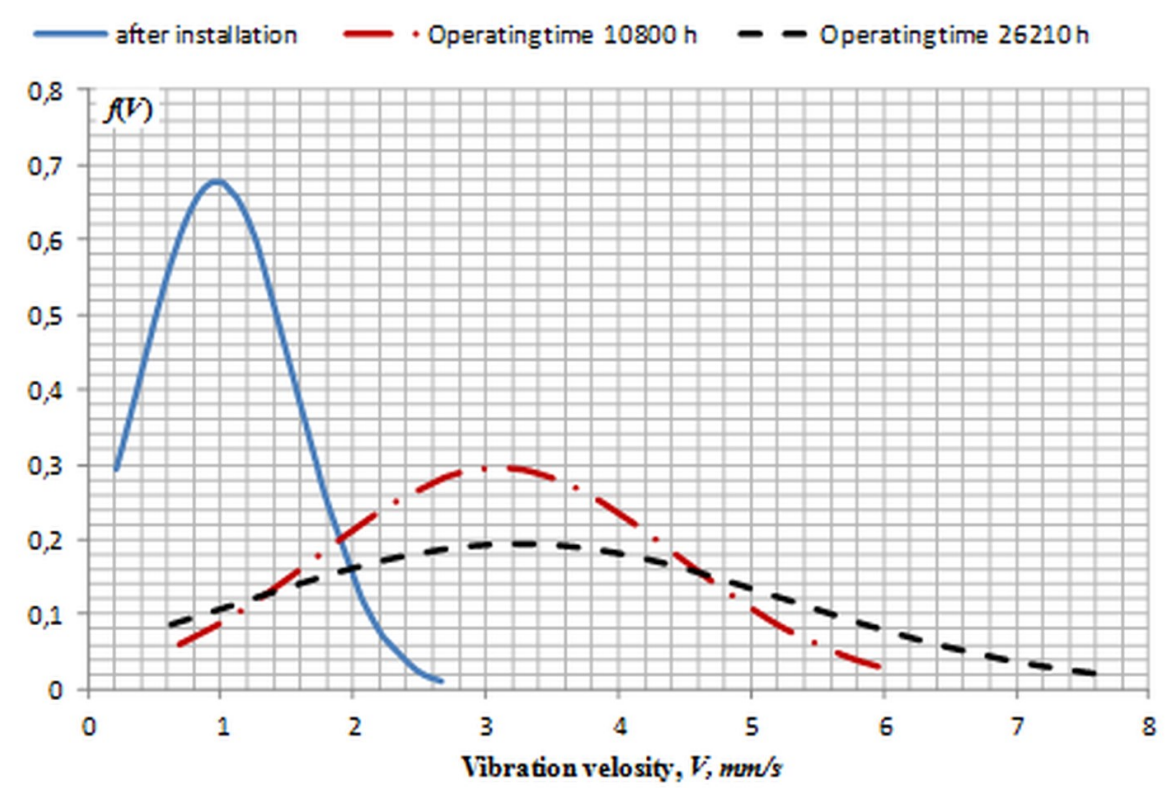

Fig. 1. The distribution of the overall level of Gauss's vibration.

Chart analysis (Fig. 1) shows that after burnishing the distribution of the overall level of vibration corresponds to Gauss's. After that the vibration processes in each individual drive develop uniquely. An overall vibration level after the operating time of 26210 hours exceeds the area of the warning values of $7.2 \mathrm{~mm} / \mathrm{s}$ in the few gearboxes [5]. 


\section{Definition of the problem}

In electric drives with frequency control of the angular velocity of the drive motor the frequency of the disturbing force changes significantly.The amplitudes of the system's response also change. Vibration analysis of the resulting vibrations is based on the understanding of the laws of vibration parameters changes. It makes possible to diagnose defects of the drive elements, predict the development of damage and prevent the appearance of an unacceptable condition. Timely determination of the limit state increases the operational reliability of the conveyor drive and significantly reduces the possibility of an emergency stop of the transport chain.

Any mechanical system has a natural frequency of oscillation. If the natural frequency of the drive oscillates with the perturbing frequency or response frequency, resonance may occur. The excitation of two oscillations with different frequencies in a nonlinear system leads to the occurrence of oscillations at multiple, differential, or total frequencies. If you change the exciting frequency, the overall vibration level will also change.

For gearboxes of a frequency-controlled electric drive, which makes system oscillate, the frequency varies according to the needs of the technological process. Thus, to determine the technical condition of the gearbox elements is necessary to develop new evaluation criteria at lower speeds of the belt.

Diagnosing the state of the conveyor drive elements and the subsequent assessment of the danger degree of failure based on vibration control data are one of the most effective methods for improving reliability during operation [6].

Creating a mathematical description of the vibration state of the machine is the first and most important stage in conducting vibration diagnostics. At the next stage, it is necessary to identify the characteristic diagnostic signs of defects. The final stage will be the decision to involve into the operation of the machine and conduct its maintenance or repair $[7,8]$.

The proposed method takes into account the characteristics of a controlled electric drive, in which the reverse frequency of an electric motor varies according to the needs of the technological process. It is the introduction of so-called "floating support masks" (floating spectrum mask). The floating support mask is created by using the original spectrum of an operable mechanism at the corresponding speed of the high-speed shaft $f_{r}$ (we will call it "the rotor speed").

\section{Research result}

Let us choose four main modes of operation of the conveyor, as a percentage of the nominal speed of the drive. An approximate compliance of the modes and the values of the reverse frequency is given in Table 1 .

Table 1. The value of the rotor speed for different modes of operation of the conveyor.

\begin{tabular}{|c|l|c|c|}
\hline $\begin{array}{c}\text { Conveyor } \\
\text { Mode }\end{array}$ & $\begin{array}{l}\text { Approximate Provision of the } \\
\text { technological Process }\end{array}$ & $\begin{array}{c}\text { Percentage of } \\
\text { Rated Speed, } \%\end{array}$ & $\begin{array}{c}\text { The Value of the } \\
\text { Rotor Speed, } f_{r}, \mathbf{H z}\end{array}$ \\
\hline 1 & $\begin{array}{l}\text { All the preparatory faces and } \\
\text { longwall are working }\end{array}$ & 100 & 25 \\
\hline 2 & Longwall are working preparatory faces are & 75 & 18.75 \\
\hline 3 & $\begin{array}{l}\text { Two pre } \\
\text { working }\end{array}$ & 50 & 12.5 \\
\hline 4 & One preparatory face is working & 25 & 6.25 \\
\hline
\end{tabular}

On the basis of the experimental data of vibration spectra collected from a number of single-type gearboxes of mine belt conveyors, for common speed $\beta$ modes, generalized 
spectra were constructed and the values of preventive reference spectral masks of vibration were calculated (Fig. 2-4).

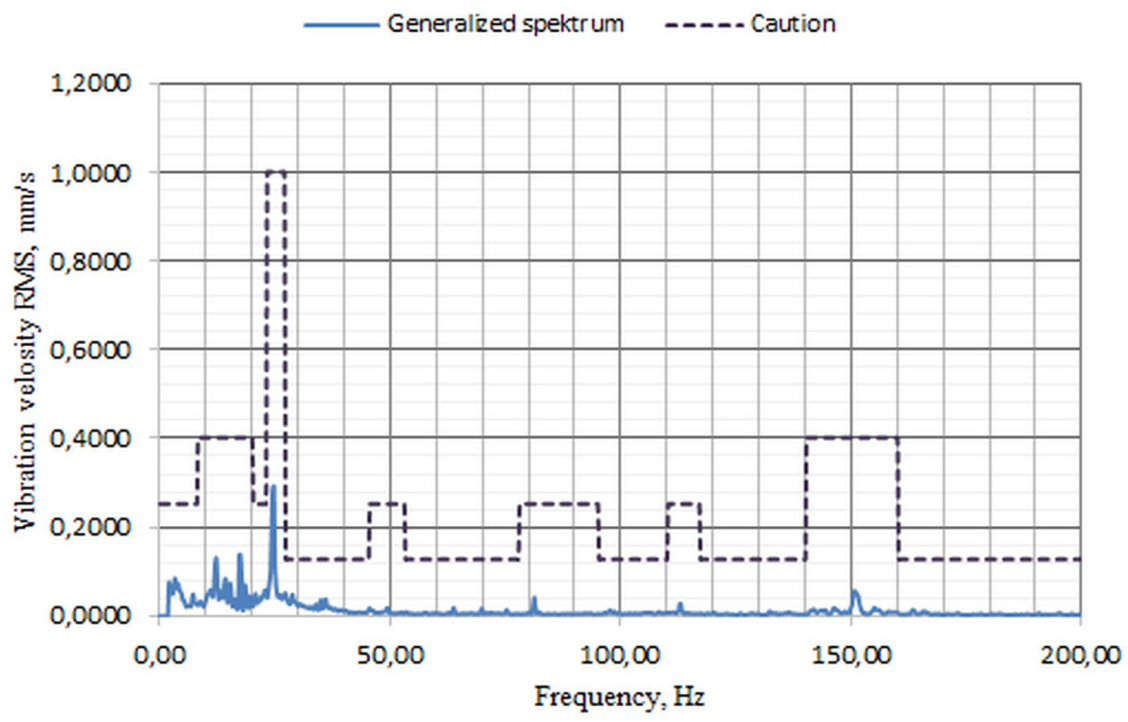

Fig. 2. Generalized spectrum and spectral mask level "warning" at the nominal frequency of rotation, $\beta=1$.

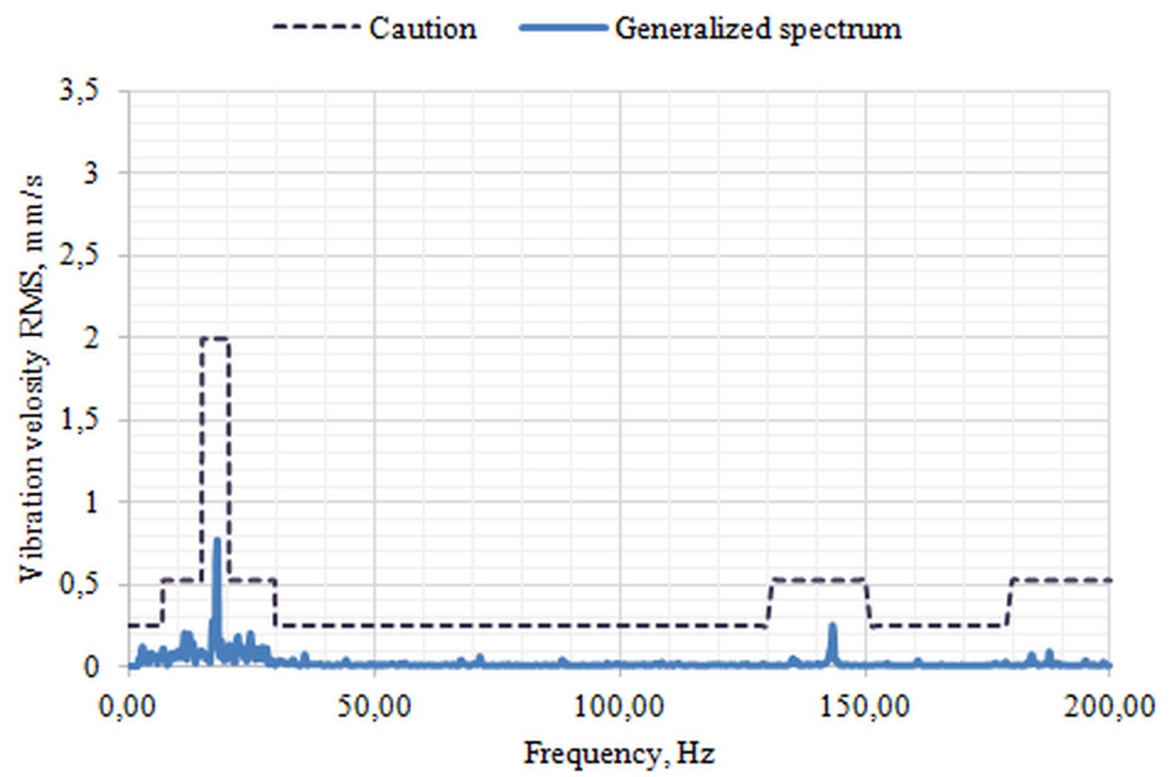

Fig. 3. Generalized spectrum and spectral mask of the "warning" level at a frequency of rotation reduced by $25 \%, \beta=0,75$. 


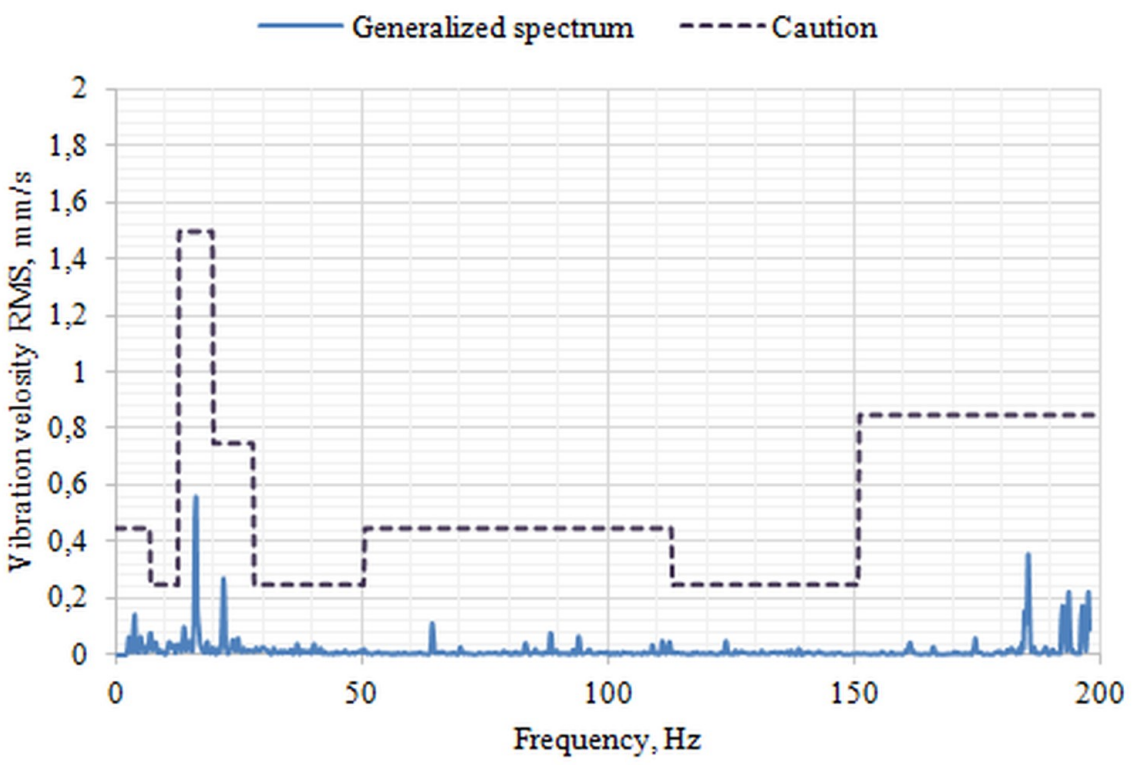

Fig. 4. Generalized spectrum and spectral mask of the "warning" level at a frequency of rotation reduced by $50 \%, \beta=0,5$.

It should be notice that the value of the synchronous frequency of rotation of the stator field (ideal idling) is indicated. The real frequencies will be less by the amount of slip, depending on the actual loading of the belt.

It is proved that the reference spectrum should have an extension in frequency of $4 \div 6 \%$. The initial support mask can be taken as a "generalized spectrum" - a spectrum corresponding to the serviceable condition of single-type gearboxes $[9,10]$.

The reference masks of the "warning" level are given for the nominal rotation frequency (Fig. 1), at a rotation frequency of $75 \%$ (Fig. 2), at a rotation frequency of $50 \%$ (Fig. 3). When the rotational speed is reduced by $25 \%$, the vibration level at the rotational frequency of the rotor becomes higher than at the nominal frequency. This is caused by the coincidence of the exciting frequency oscillations with the natural frequency of the system.

When comparing the new spectrum with the "reference mask", any vibration amplitude levels exceeding the mask contours (the so-called "mask puncture") can be considered as a sign of malfunction. The frequency values are used at which the faults are manifested [11].

The results of vibration diagnostics of the gearbox having an operating time of 22500 hours are shown in Fig. 5. At the time of the survey, the nominal rate was $75 \%$. The load characteristics of the belt conveyor corresponded to mode 2 (table 1). The puncture of the mask characterizes the wear of the high-speed shaft bearings, as well as the gear pair of the second shaft of the reducer. If the condition of the reducer is recognized as restrictively usable, the next measurement of vibration should be carried out in a month. 


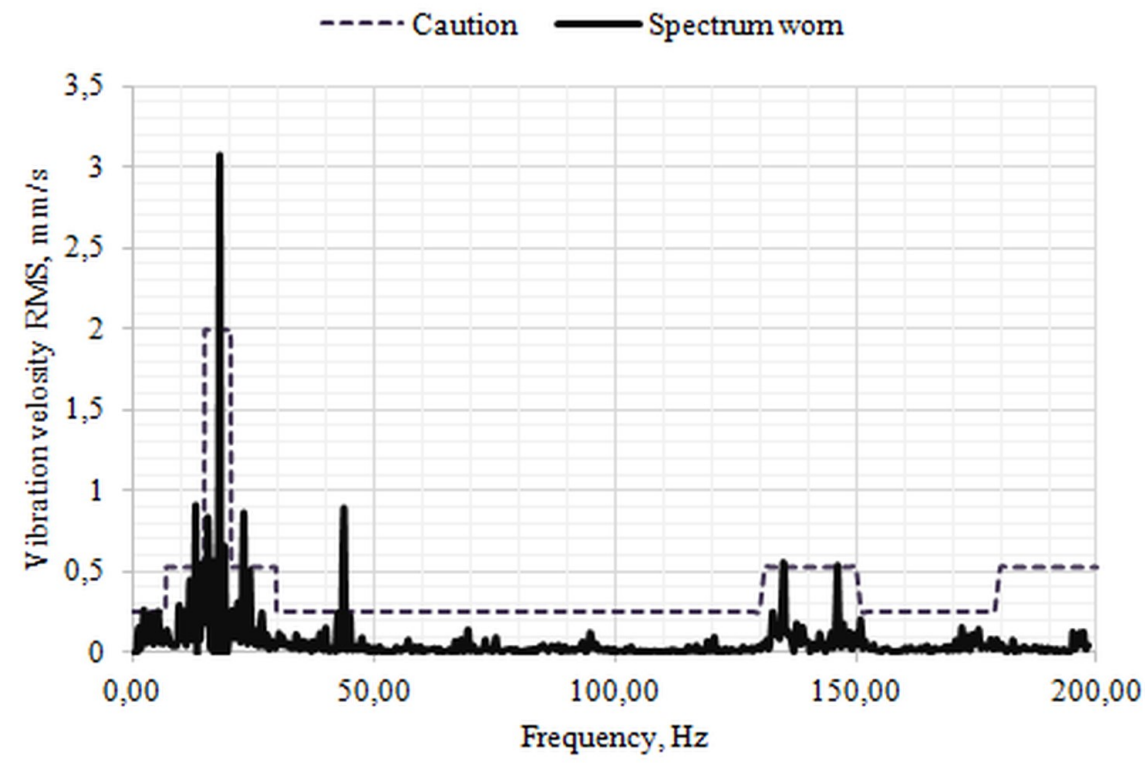

Fig. 5. Vibration spectrum characterizing the wear of the gearbox.

Similarly, floating reference mask "alarm" are made according to the warning level. The reference mask "alarm" is obtained by increasing the warning value by 2.5 times, which corresponds to the standards.

\section{Conclusion}

Thus, the conducted research confirmed the effectiveness of the method of floating support spectral masks for monitoring the technical condition of the elements and components of gearboxes of mine belt conveyors. Mine belt conveyors operate in very difficult conditions at hazardous production facilities. The failure of the conveyor reducer affects the operation of the entire treatment complex, while the replacement time can reach 24 hours, and lead to potential losses of coal mining companies. Systematic monitoring of the condition allows not only to detect defects at an early stage, but also to predict the development of defects. The introduction of the technique in the diagnosis system results to the cost reductions of the technical maintenance. In addition, it provides a stable safety of the personnel.

\section{References}

1. J. Obuchowski et al, Appl. Mech. Mater., 683, 171 (2014)

2. W. Bartelmus, KEM, 588, 184 (2014)

3. Z. Ming, J. Xiaodong, MSSP, 94, 129 (2017)

4. L.Jing, M. Zhao, P. Li, X. Xu, Measurement, 111, 1 (2017)

5. E. Kuzin, B. Gerike, Y. Drozdenko et al. IOP Conf. Series: Mater. Sci. Eng, 253, 012013 (2017)

6. B. Gerike, I. Panachev, E. Kuzin, E3S Web Conf., 15, 03008 (2017)

7. G. E. Morales-Espejel, Evolution, 2, 25-30 (2010)

8. A. Mohamed, S. Sassi \& M. Paurobally, Shock Vib., 2018, 1913289 (2018) 
9. W. Yu, Y. Shao, and C. Mechefske, Eng. Fail. Anal., 54, 103 (2015)

10. K. Heidarbeigi, H. Ahmadi, M. Omid and A. Tabatabaeefar, J. Agric. Sci. Technol, 5, 1 (2009)

11. L. Saidi, J. Ben Ali, F. Fnaiech, ISA Transactions, 53, 1650 (2014) 